\title{
Microstructure and texture dependence of the dielectric anomalies and dc conductivity of $\mathrm{Bi}_{3} \mathrm{TiNbO}_{9}$ ferroelectric ceramics
}

\author{
A. Moure ${ }^{\text {a) }}$ and L. Pardo \\ Instituto de Ciencia de Materiales de Madrid, Consejo Superior de Investigaciones Cientificas (CSIC), \\ Cantoblanco 28049, Madrid, Spain
}

(Received 5 October 2004; accepted 13 January 2005; published online 7 April 2005)

Ceramics of composition $\mathrm{Bi}_{3} \mathrm{TiNbO}_{9}(\mathrm{BTN})$ and perovskite-layered structure (Aurivillius type) [B. Aurivillius, Ark. Kemi 1, 463 (1949)] were processed by natural sintering and hot pressing from amorphous precursors. Precursors were obtained by mechanochemical activation of stoichiometric mixtures of oxides. These materials are in general interesting for their use as high-temperature piezoelectrics. Among them, BTN possesses the highest ferroparaelectric phase-transition temperature $\left(>900{ }^{\circ} \mathrm{C}\right)$. The transition temperature establishes the working limit of the ceramic and the electric properties, especially the dc conductivity, affect on its polarizability. In this work, dielectric studies of BTN ceramics with controlled texture and microstructure have been made at $1,100 \mathrm{KHz}$, and $1 \mathrm{MHZ}$ and in the temperature range from $200{ }^{\circ} \mathrm{C}$ up to the ferroparaelectric transition temperature. Values of $\varepsilon^{\prime} \sim 250$ at $200^{\circ} \mathrm{C}$ are achieved in ceramics hot pressed at temperatures as low as $700{ }^{\circ} \mathrm{C}$ for $1 \mathrm{~h}$. (C) 2005 American Institute of Physics. [DOI: 10.1063/1.1865313]

\section{INTRODUCTION}

Aurivillius-type structure compounds ${ }^{1}$ have as general formula $\left[\mathrm{Bi}_{2} \mathrm{O}_{2}\right]\left[\mathrm{A}_{n-1} \mathrm{~B}_{n} \mathrm{O}_{3 n+1}\right]$, built up by $n[\mathrm{ABO}]^{2-}$ layers that alternates with $\left[\mathrm{Bi}_{2} \mathrm{O}_{2}\right]^{2+}$ layers. These compounds are also known as bismuth-layered structure ferroelectrics (BLSF) and are characterized by a high ferroparaelectric transition temperature. They are good candidates for their use as high-temperature piezoelectrics. ${ }^{2}$ Moreover, their low fatigue, high polarization retention, and low leakage currents make them interesting for nonvolatile ferroelectric random access memories (FERAMs) when they are prepared as thin films. ${ }^{3}$

As it happens in other compositions with similar crystalline structure, it is difficult to obtain dense ceramics of $\mathrm{Bi}_{3} \mathrm{TiNbO}_{9}$ (hereinafter called $\mathrm{BTN}$ ) when they are prepared by solid-state reaction due to the growth habit. It gives place to lamella-like particles, ${ }^{4}$ due to the anisotropy of the crystalline structure, which are difficult to compact. When they are prepared by hot pressing, the largest faces of the grains arrange perpendicular to the applied pressure, resulting in highly dense ceramics but with anisotropic properties. ${ }^{5,6} \mathrm{An}$ alternative route is used in this work. Starting from highly reactive precursors, it is possible to obtain ceramics with controlled texture and microstructure at moderate temperatures. These precursors are obtained from mechanochemical activation, by highly energetic milling, of oxides and carbonates mixtures, and they are amorphous. ${ }^{7}$ In this way, it is possible to obtain by sintering isotropic ceramics with lower porosity than if crystalline precursors obtained by solid-state reaction are used, ${ }^{4}$ and at lower processing temperatures.

The transmission electron microscopy (TEM) studies and quantitative microstructure and texture analysis of hotpressed BTN ceramics from mechanically activated precur-

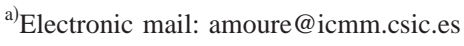

sors have also been accomplished. ${ }^{8,9}$ As an outline of the results obtained in these studies, it can be said that the hotpressed ceramics have lower porosity $(<1 \%)$ than the sintered ones $(8 \%-25 \%)$ and, also, that depending on the treatment temperature, isotropic or textured ceramics can be obtained. Ceramics are isotropic when they are hot pressed at low temperature $\left(700-1000{ }^{\circ} \mathrm{C}\right)$, due to the lack of a lamella-like shape grains development, as TEM studies show. ${ }^{9}$ At higher temperature $\left(1050{ }^{\circ} \mathrm{C}\right.$ for $\left.1 \mathrm{~h}\right)$, the typical texture of Aurivillius-type structure ceramics is developed, and the grains arrange with the $c$ axis of the perovskite in parallel to the applied pressure.

Dielectric properties of these materials, especially their conductivity, are determinant in the poling process using high electric fields, and in the piezoelectric activity at high temperatures. The influence of the porosity and the grain size in the properties of ferroelectric ceramic materials has been widely studied, mainly in perovskite-type structure materials. ${ }^{10-12}$ In the case of BLSF materials, only few works have focused on these effects. Most of them have centered in modified $\mathrm{Bi}_{4} \mathrm{Ti}_{3} \mathrm{O}_{12}(n=3){ }^{13-15}$ Others have studied systems with $n=2$, as $\mathrm{SrBi}_{2} \mathrm{Ta}_{2} \mathrm{O}_{9} \cdot{ }^{16}$ However, the dielectric properties of BTN ceramics have been scarcely studied ${ }^{17,18}$ and its relation with microstructure in the full temperature interval up to the ferroparaelectric phase transition has not yet been accomplished, mainly due to its high conductivity at those temperatures.

Among the BLSF materials, BTN has the highest ferroparaelectric phase-transition temperature $\left(T_{C}>900{ }^{\circ} \mathrm{C}\right)$. Impedance measurements of BTN ceramics up to the ferroparaelectric transition temperatures have been performed in this work. From them, permittivity, dielectric loss factor, and dc conductivity have been calculated. As it has been explained, the use of mechanically activated precursors allows having ceramics with controlled texture and microstructure. 
This fact makes possible to study separately the influence of the porosity (comparing ceramics sintered and hot pressed) and the grain size (comparing hot-pressed ceramics, with negligible porosity and different grains sizes) on the dielectric properties of the ceramics.

\section{EXPERIMENT}

Ceramics of composition $\mathrm{Bi}_{3} \mathrm{TiNbO}_{9}$ have been prepared from stoichiometric mixtures of analytical grade $\mathrm{Bi}_{2} \mathrm{O}_{3}$, $\mathrm{Nb}_{2} \mathrm{O}_{5}$, and $\mathrm{TiO}_{2}$, amorphous according to $\mathrm{x}$-ray diffraction analysis ${ }^{7}$ after mechanical activation. This precursor powder is uniaxially pressed at $300 \mathrm{Kg} \mathrm{cm}^{-2}$ to obtain disks of approximately $10-\mathrm{mm}$ diameter and 2-mm thickness. Some of these disks are isostatically pressed at $2000 \mathrm{Kg} \mathrm{cm}^{-2}$, and sintered in furnace at temperatures from 1000 to $1100{ }^{\circ} \mathrm{C}$ for 1 or $2 \mathrm{~h}$. Other disks are surrounded by alumina powder and hot pressed in alumina dies, at temperatures from 700 to $1050{ }^{\circ} \mathrm{C}$ and $\sim 200 \mathrm{Kg} \mathrm{cm}^{-2}$ during $1 \mathrm{~h}$.

Ceramic surfaces were polished and analyzed by optical microscopy (Leitz Laborlux $12 \mathrm{ME} \mathrm{S/ST)} \mathrm{before} \mathrm{and} \mathrm{after}$ thermal etching in order to examine the porosity, and the grain size and morphology, respectively. Quantitative characterization was carried out with a computerized image analysis and measurement system (IMCO10-KAT386 system, Kontron Elektronic GMBH, 1990) by a procedure explained elsewhere. ${ }^{19}$ The ceramic porosity was characterized in this work by the pore area distribution and by the percentage of porosity, obtained as the area fraction occupied by pores. Due to the lamellar morphology of the grains, we calculate the aspect ratio, i.e., the relation between the maximum and minimum lengths of the grain, obtained after measuring the Feret diameters ${ }^{20}$ in 32 directions. The mean value of the aspect ratio was obtained from linear fitting of the experimental data represented in probability plots. ${ }^{21}$ In these plots, the Ln of the variable being studied is represented against the corresponding cumulative frequency in a probability scale.

Impedance measurements, between $100 \mathrm{~Hz}$ and $5 \mathrm{MHz}$ and as a function of temperature (from 200 to $950{ }^{\circ} \mathrm{C}$ ), were performed with an HP4194A analyzer on parallel faces ceramics with painted $\mathrm{Pt}$ electrodes sintered at $700{ }^{\circ} \mathrm{C}$, in an experimental setup for the temperature control described elsewhere. ${ }^{6}$ The heating and cooling rates were $2{ }^{\circ} \mathrm{C} / \mathrm{min}$, stabilizing the temperature for $1 \mathrm{~min}$. From these experimental data and the sample geometry, complex permittivity, $\varepsilon^{*}$ $=\varepsilon-i \varepsilon^{\prime \prime}$, and dielectric loss factor, $\tan \delta$, were obtained. The dc conductivity was calculated by fitting impedance arcs, $Z^{\prime}-Z^{\prime \prime}$, using the EQUIVCRT program (B. A. Boukamp. AC Inmitance Data Analysis System Equivalent Circuit. Version 4.50. University of Twente. Twente.1999). This program uses a processing of nonlinear least-squares-fit technique that allows the simultaneous determination of all the parameters of the equivalent circuit, as it is described in detail elsewhere. ${ }^{22}$ These equivalent circuits comprises 1 or 2 (depending on the temperature) $R Q C$ circuits in series, each one consisting of a resistance $(R)$ in parallel to a capacitor $(C)$ and to a constant phase element $(Q)$. To start the calculus, one needs to introduce some initial values. With this aim, the program calculates circles, with three experimental data in each one, to

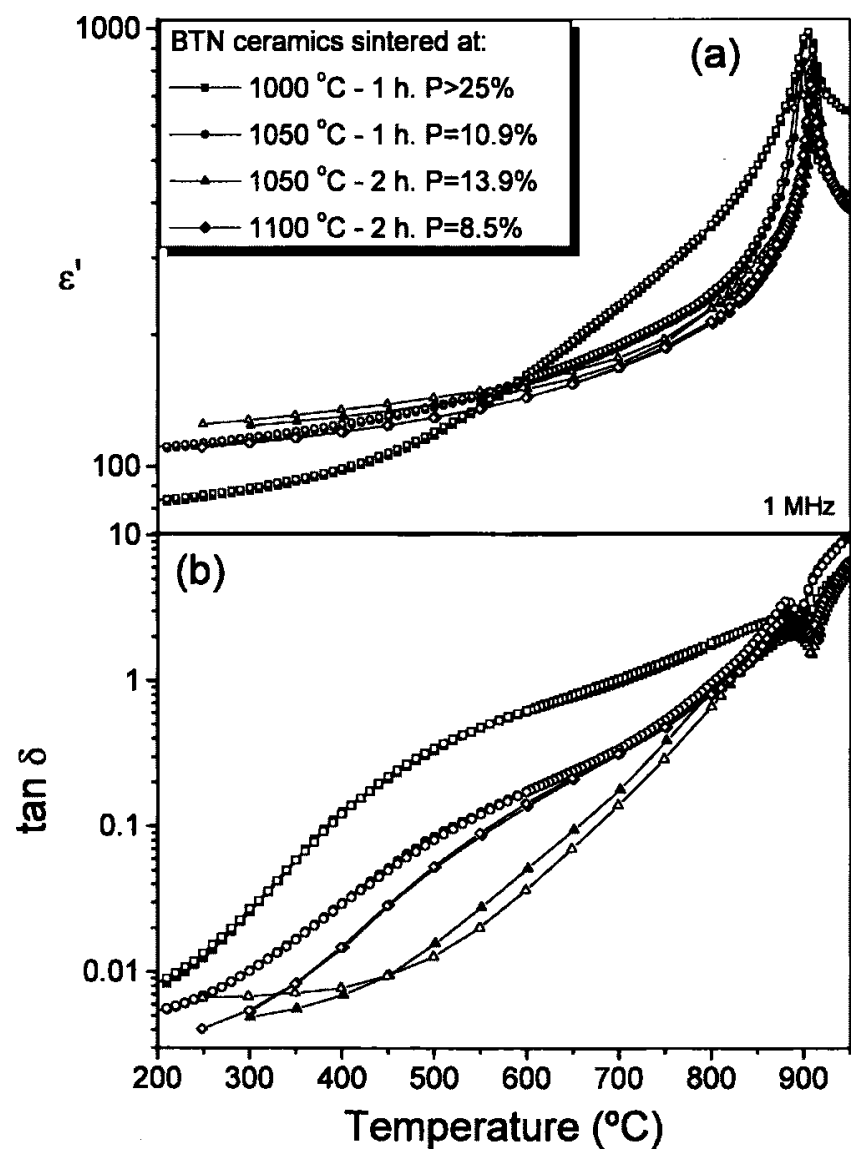

FIG. 1. Real part of dielectric permittivity and dielectric loss factor at $1 \mathrm{MHz}$ as a function of temperature for $\mathrm{Bi}_{3} \mathrm{TiNbO}_{9}$-sintered ceramics (solid symbols: heating; hollow symbols: cooling).

have the initial values of $R$ and $Q$ for each $R Q C$ subcircuit. The value of $C$ is taken as the capacity at high frequencies, which is usually constant at frequencies higher than $10 \mathrm{KHz}$. From these initial data, the nonlinear least-squares fit by an iterative calculus is performed. This process was repeated at each temperature, which allows obtaining the $R$ values with the minimum relative errors. The inverse of them, multiplied by a geometric factor, thickness/area, gives the dc conductivity of the ceramics.

\section{RESULTS}

Figure 1(a) shows the real part of the dielectric permittivity at $1 \mathrm{MHz}$ as a function of temperature of the BTNsintered ceramics. Values of porosity determined by quantitative microscopy ${ }^{8}$ are shown in the legend for the ceramics under study. Figure 1(b) shows the dependence of the dielectric loss factor in the same ceramics. Both heating and cooling runs are shown. Closer to room temperature (at $200{ }^{\circ} \mathrm{C}$ ), the highest value of permittivity corresponds to the ceramic sintered at $1050{ }^{\circ} \mathrm{C}$ for $2 \mathrm{~h}\left(\varepsilon^{\prime}=123\right)$, and the lowest one to the sintered at $1000{ }^{\circ} \mathrm{C}$ for $1 \mathrm{~h}\left(\varepsilon^{\prime}=84\right)$, that also presents a broader maximum. This relation is inverted at higher temperatures, and it is this latter ceramic which has the highest value $\left(\varepsilon^{\prime}=967\right)$ at the peak of the ferroparaelectric phase transition. The temperature of the maximum of permittivity varies slightly (between 900 and $915^{\circ} \mathrm{C}$ ) depending on the sintering conditions. 


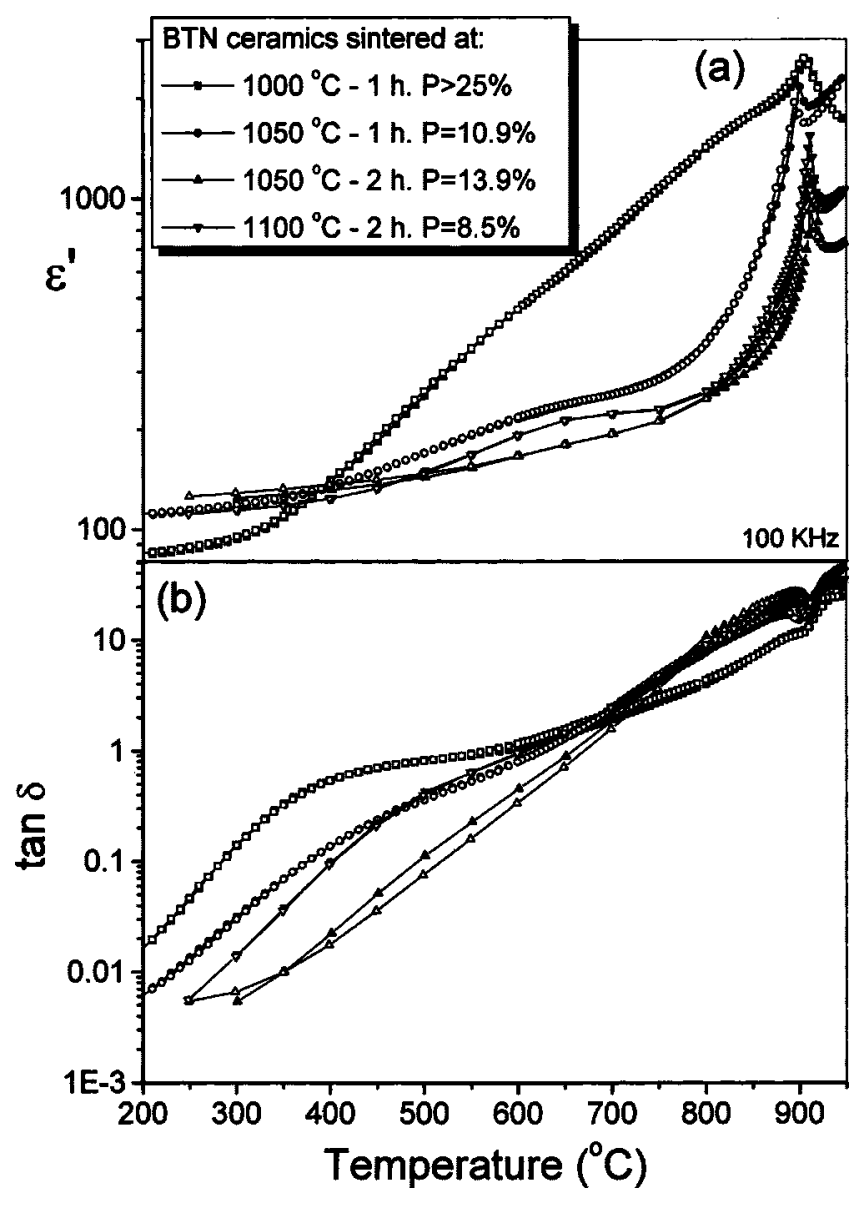

FIG. 2. Real part of dielectric permittivity and dielectric loss factor at $100 \mathrm{KHz}$ as a function of temperature for $\mathrm{Bi}_{3} \mathrm{TiNbO}_{9}$-sintered ceramics (solid symbols: heating; hollow symbols: cooling).

All the ceramics have a local maximum in the loss factor at temperatures slightly lower than the ferroparaelectric phase-transition one, and a local minimum at the temperatures of the maximum of permittivity. At the cooling run, those maximums are displaced to lower temperatures. Closer to room temperature, the dielectric losses are similar for all the ceramics. That sintered at $1000{ }^{\circ} \mathrm{C}$ for $1 \mathrm{~h}$ presents the highest values in the temperature range below the maximum.

Figures 2(a) and 3(a) show the evolution of the real part of the permittivity with temperature for the BTN-sintered ceramics, in the heating and cooling runs, at 100 and $1 \mathrm{KHz}$, respectively. Figures 2(b) and 3(b) show the dielectric loss factors at the same frequencies. The characteristic peak corresponding to the phase transition cannot be distinguished at $1 \mathrm{KHz}$. At that frequency, a shoulder can be appreciated between 400 and $600{ }^{\circ} \mathrm{C}$, in both heating and cooling runs. In the ceramic sintered at $1000{ }^{\circ} \mathrm{C}$ for $1 \mathrm{~h}$ an additional anomaly located at higher temperature $\left(650-750^{\circ} \mathrm{C}\right)$ is observed.

The properties of the BTN ceramics hot pressed at 700, 900 , and $1000{ }^{\circ} \mathrm{C}$ are represented all together because, as it was pointed out in the introduction, they are isotropic. ${ }^{8}$ It has been previously reported that $1000{ }^{\circ} \mathrm{C}$ for $1 \mathrm{~h}$ represents the upper limit of hot-pressing temperature to obtain isotropic ceramics. ${ }^{8}$ An increase in the hot-pressing temperature increases the grain area, and due to the anisotropic growth

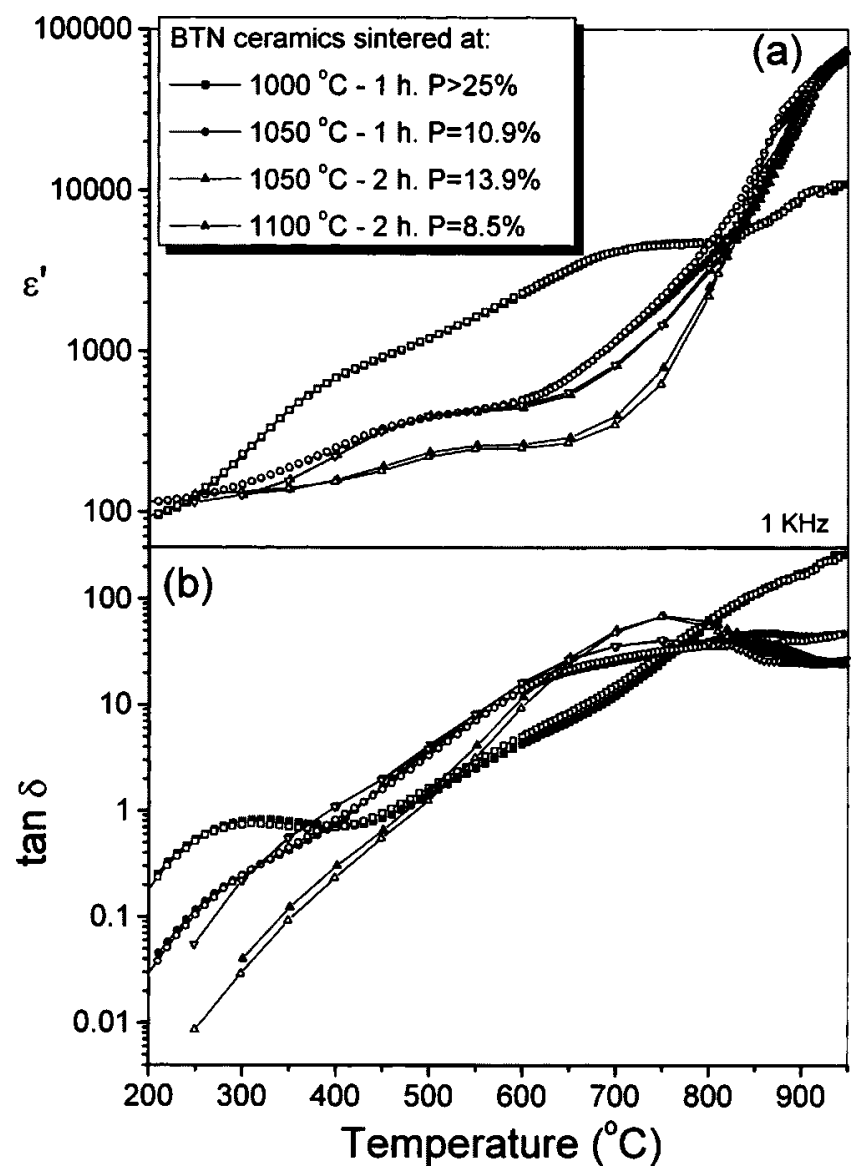

FIG. 3. Real part of dielectric permittivity and dielectric loss factor at $1 \mathrm{KHz}$ as a function of temperature for $\mathrm{Bi}_{3} \mathrm{TiNbO}_{9}$-sintered ceramics (solid symbols: heating; hollow symbols: cooling).

habit in ceramics with Aurivillius-type structure, the aspect ratio also increases. It favors the arrangement of the grains and the appearance of texture. To illustrate this point, Fig. 4 shows the optical micrographs of the perpendicular and parallel to the applied pressure sample cuts for BTN ceramics hot pressed at 1000 and $1050{ }^{\circ} \mathrm{C}$ for $1 \mathrm{~h}$. No differences between the cuts are found in the former, while in the latter a certain degree of arrangement of grains is observed in the so-called parallel sample cut. The anisotropy of the microstructure and the texture developed are linked and consequence of the anisotropy of the crystal structure and growth habit.

Figure 5 shows the probability plots of the aspect ratio of the grains for each sample cut for the ceramics hot pressed at 1000 and $1050{ }^{\circ} \mathrm{C}$ for $1 \mathrm{~h}$. From them, mean values of the aspect ratio have been calculated. Values of 1.9 and 2.0 are found for the perpendicular and parallel to the applied pressure sample cuts, respectively, for the ceramic hot pressed at $1000{ }^{\circ} \mathrm{C}$ for $1 \mathrm{~h}$. The aspect ratios are 2.4 (perpendicular) and 2.6 (parallel) for the ceramic hot pressed at $1050{ }^{\circ} \mathrm{C}$ for $1 \mathrm{~h}$, revealing the lamellar morphology.

Figure 6(a) shows the real part of $\varepsilon^{\prime}$ at $1 \mathrm{MHz}$ as a function of temperature of the BTN ceramics hot pressed at 700,900 , and $1000{ }^{\circ} \mathrm{C}$. As for the sintered ceramics, values of porosity determined by quantitative microscopy ${ }^{8}$ are added in the legend of Figs. 6-8 where the same data are shown for 100 and $1 \mathrm{KHz}$, respectively. The hot-pressed iso- 


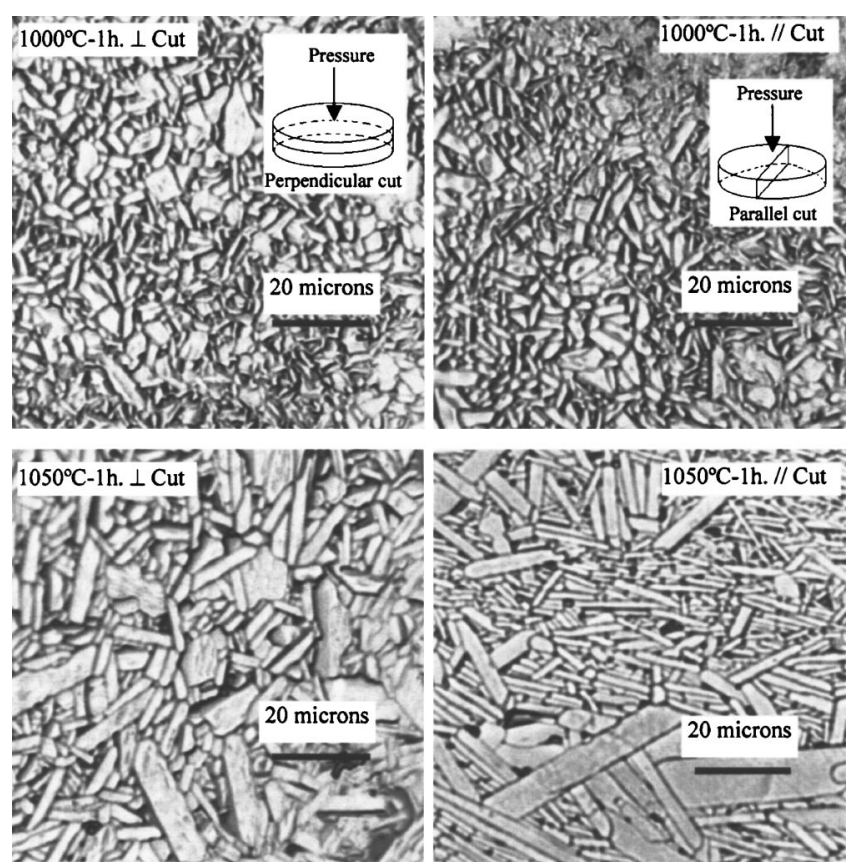

FIG. 4. Optical micrographs of polished and thermally etched surfaces of $\mathrm{Bi}_{3} \mathrm{TiNbO}_{9}$ ceramics hot pressed at 1000 and $1050{ }^{\circ} \mathrm{C}$ for $1 \mathrm{~h}$, in both perpendicular and parallel to the applied pressure sample cuts.

tropic ceramics have higher $\varepsilon^{\prime}$ values [Fig. 6(a)] than the naturally sintered ones $\left(\varepsilon^{\prime} \sim 250\right.$ at $240{ }^{\circ} \mathrm{C}$ for the ceramic hot pressed at $700{ }^{\circ} \mathrm{C}$ for $1 \mathrm{~h}$ ). The permittivity decreases as the hot-pressing temperature increases, and simultaneously

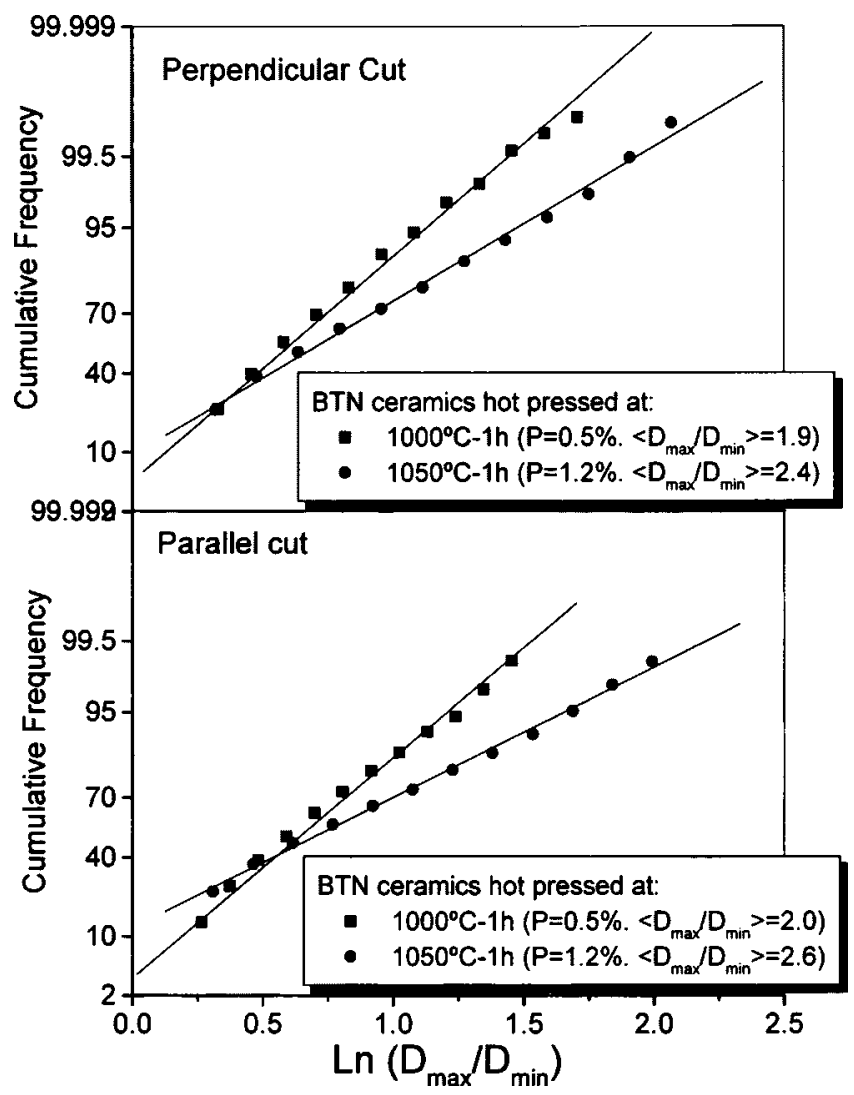

FIG. 5. Probability plots of the aspect ratio of grains of $\mathrm{Bi}_{3} \mathrm{TiNbO}_{9}$ ceramics hot pressed at 1000 and $1050{ }^{\circ} \mathrm{C}$ for $1 \mathrm{~h}$, in both perpendicular and parallel to the applied pressure sample cuts.

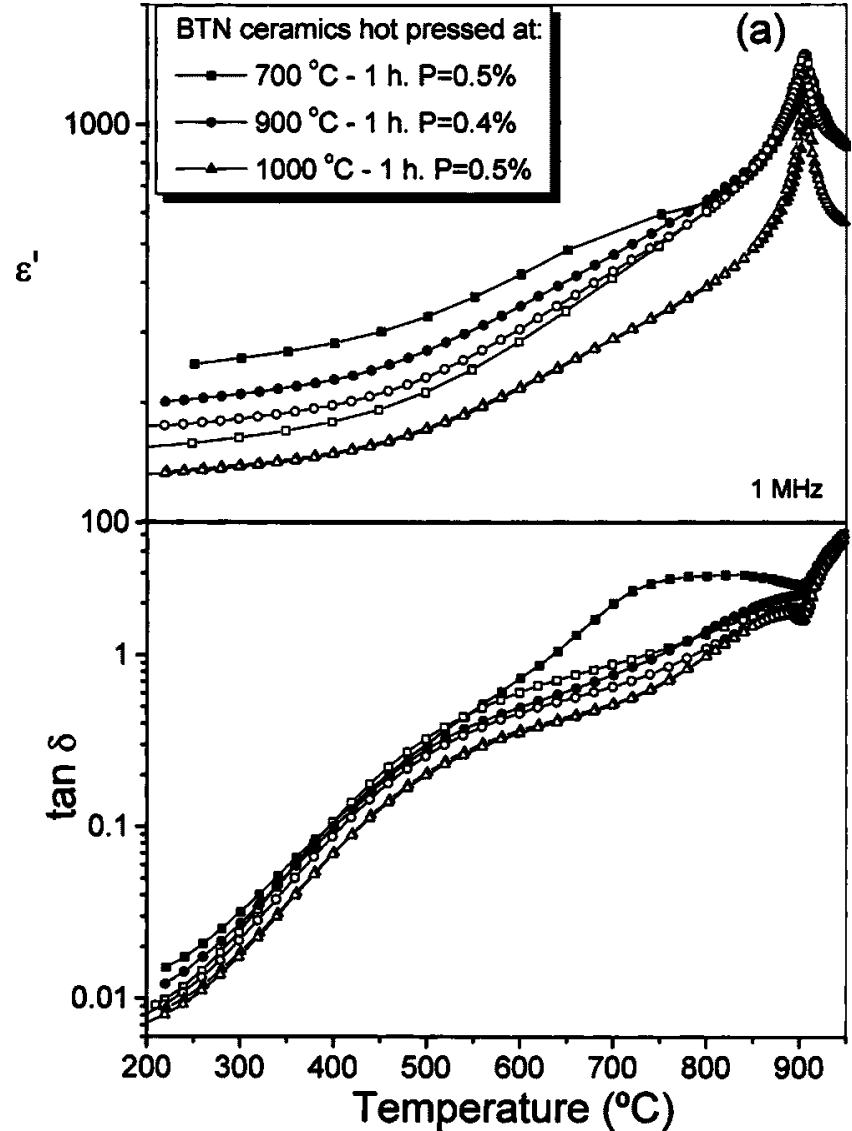

FIG. 6. Real part of dielectric permittivity and dielectric loss factor at $1 \mathrm{MHz}$ as a function of temperature for $\mathrm{Bi}_{3} \mathrm{TiNbO}_{9}$ hot-pressed ceramics (solid symbols: heating; hollow symbols: cooling).

the peak becomes narrower. In contrast to the sintered ceramics, there is no displacement in the temperatures of the maximums with the different processing conditions. As for the sintered ceramics, a decrease in the temperature of the maximum of permittivity during the cooling run is observed.

There are big differences in the heating and cooling runs of the permittivity of the ceramics hot pressed at 700 and $900{ }^{\circ} \mathrm{C}$ for $1 \mathrm{~h}$. The values of $\varepsilon^{\prime}$ and $\tan \delta$ in the cooling run are very similar for both ceramics, suggesting that the thermal cycle of the measurements, up to a temperature $\left(950^{\circ} \mathrm{C}\right)$ well above the processing one, acts as a post hot-pressing thermal treatment. Most probably, it gives place to microstructural changes. It was recently proved ${ }^{23}$ that if hotpressed ceramics are heated to a temperature higher than the initial hot-pressing one, in a so-called recrystallization process, a certain degree of porosity is developed in the ceramic and an increase in the grain area and aspect ratio is produced. They both depend on the difference between initial and final processing temperatures. In the ceramic hot pressed at $1000{ }^{\circ} \mathrm{C}$ for $1 \mathrm{~h}$, noticeable differences between heating and cooling runs cannot be appreciated.

The shape of the loss factor at $1 \mathrm{MHz}$ of the hot-pressed ceramics is similar to the sintered ones, as it is shown in Fig. 6(b). The hot-pressed one at $700{ }^{\circ} \mathrm{C}$ for $1 \mathrm{~h}$ has the highest dielectric losses up to $\sim 800^{\circ} \mathrm{C}$, and the hot pressed ceramic at $1000^{\circ} \mathrm{C}$ for $1 \mathrm{~h}$ has the highest losses at the maximum $\left(\tan \delta=4.87\right.$ at $\left.886^{\circ} \mathrm{C}\right)$. 


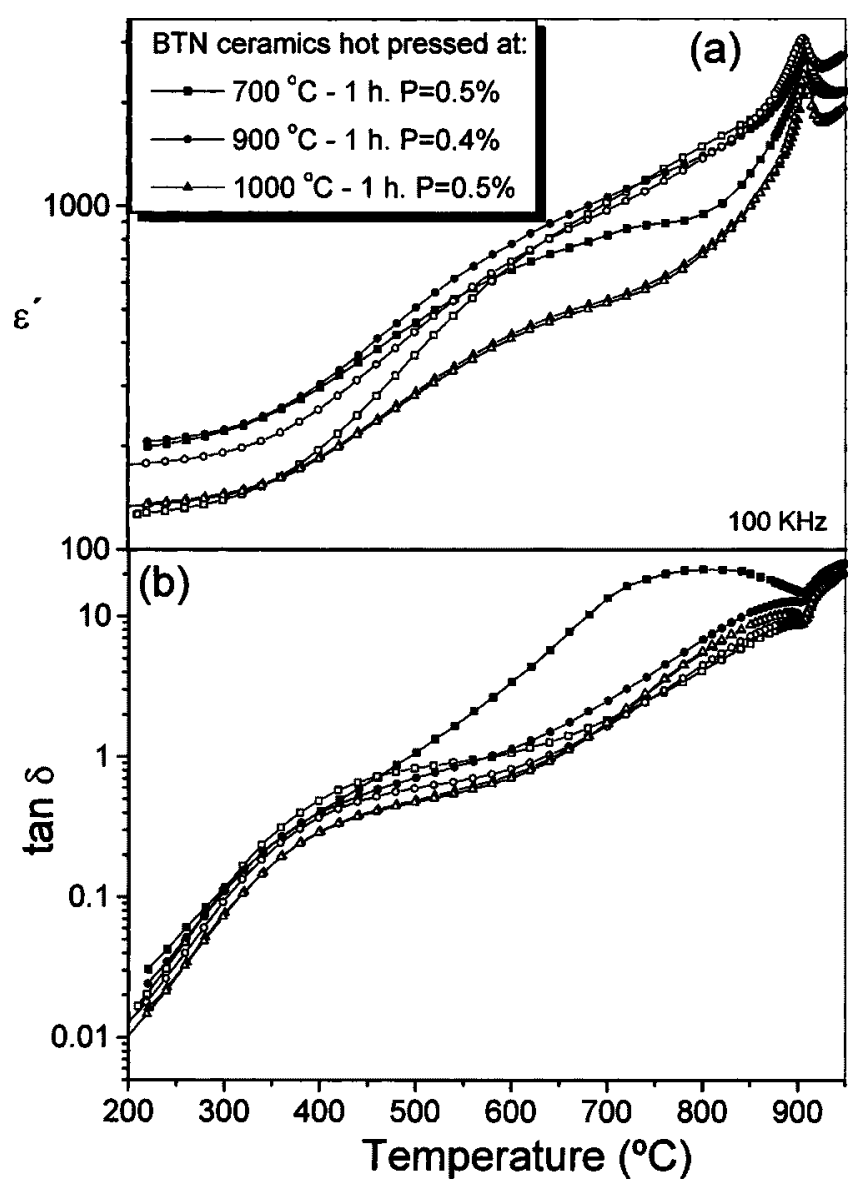

FIG. 7. Real part of dielectric permittivity and dielectric loss factor at $100 \mathrm{KHz}$ as a function of temperature for $\mathrm{Bi}_{3} \mathrm{TiNbO}_{9}$ hot-pressed ceramics (solid symbols: heating; hollow symbols: cooling).

As with the sintered ceramics, there is no displacement of the maximum of permittivity with frequency (Figs. 7 and 8). At 100 and $1 \mathrm{KHz}$ there are anomalies in the permittivity between 400 and $600{ }^{\circ} \mathrm{C}$, which can be observed during both heating and cooling runs. The anomaly observed between 650 and $800{ }^{\circ} \mathrm{C}$ in the ceramic hot pressed at $700{ }^{\circ} \mathrm{C}$ for $1 \mathrm{~h}$ is attributed to the recrystallization process described above.

Figures 9-11 show the dependence with temperature of the real part of the permittivity and the dielectric loss factor measured at $1 \mathrm{MHz}, 100 \mathrm{KHz}$, and $1 \mathrm{KHz}$, respectively, for a ceramic hot pressed at $1050{ }^{\circ} \mathrm{C}$ for $1 \mathrm{~h}$. Measurements in both parallel and perpendicular cuts to the applied pressure (see Fig. 4) of this textured ceramic are shown. A large difference in $\varepsilon^{\prime}$ is found in both cuts $\left(\varepsilon_{\|}^{\prime}=155 ; \varepsilon_{\perp}^{\prime}=128\right.$ at $219^{\circ} \mathrm{C}, 1 \mathrm{MHz}$ ). The perpendicular sample cut, which is representative of the properties in the $c$ axis of the layered perovskite, has the lowest values of permittivity of all the studied ceramics, including the sintered ones. Remarkable differences are not observed between heating and cooling runs. The parallel to applied pressure cut has also higher dielectric losses than the perpendicular one $\left[(\tan \delta)_{\|}=0.009\right.$; $(\tan \delta)_{\perp}=0.004$ at $\left.219^{\circ} \mathrm{C}, 1 \mathrm{MHz}\right]$ and the rest of the studied ceramics, and a higher hysteresis. The anomalies between 400 and $600{ }^{\circ} \mathrm{C}$ also appear in both cuts.

Figures 12 and 13 show the $Z^{\prime \prime}-Z^{\prime}$ impedance arcs for the ceramic sintered at $1100{ }^{\circ} \mathrm{C}$ for $2 \mathrm{~h}$ (at $261,500,700{ }^{\circ} \mathrm{C}$ )

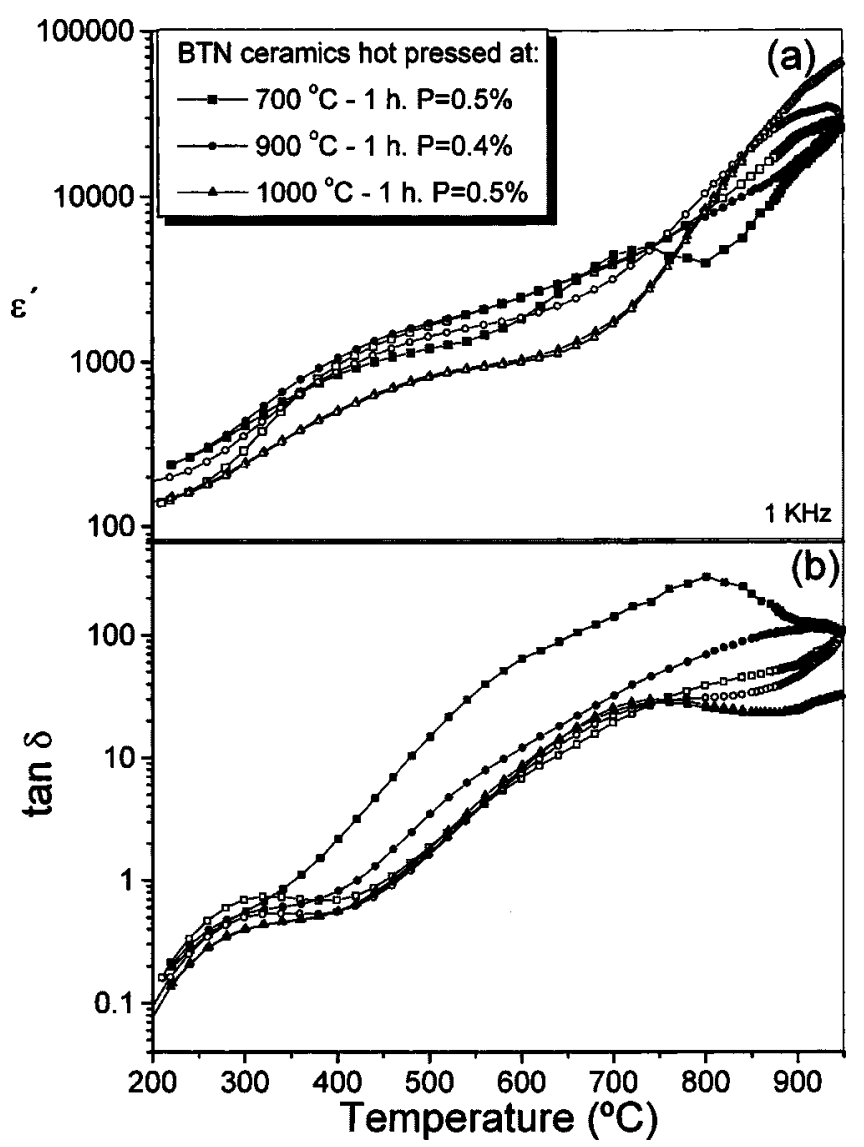

FIG. 8. Real part of dielectric permittivity and dielectric loss factor at $1 \mathrm{KHz}$ as a function of temperature for $\mathrm{Bi}_{3} \mathrm{TiNbO}_{9}$ hot-pressed ceramics (solid symbols: heating; hollow symbols: cooling).

and hot pressed at $700{ }^{\circ} \mathrm{C}$ for $1 \mathrm{~h}$ (at 221,500 , and $700{ }^{\circ} \mathrm{C}$ ), respectively. They are representative of the features observed in all the ceramics. At lower temperature $\left(<300{ }^{\circ} \mathrm{C}\right)$, two different arcs can be observed, but the one at higher frequencies disappears in the $300-700{ }^{\circ} \mathrm{C}$ range. At $T>700{ }^{\circ} \mathrm{C}$, a second arc at high frequency can be again observed up to the maximum measurement temperature $\left(950{ }^{\circ} \mathrm{C}\right)$.

From the fit of the impedance arcs, values of resistivity have been calculated, and, from them, the dc conductivity. Their Arrhenius plots for the sintered BTN ceramics can be seen in Fig. 14. As a general fact for all the ceramics, the conductivity decreases when the treatment temperature increases, except for the ceramics sintered at $1100^{\circ} \mathrm{C}$ for $2 \mathrm{~h}$, which has intermediate values. Although not well defined, three steps can be distinguished in the curves. The Arrhenius plot of the hot-pressed ceramics is shown in Fig. 15. The conductivity is higher than in sintered ceramics, especially when they are hot pressed at lower temperatures. There are three steps in the plot except for the ceramic hot pressed at $700{ }^{\circ} \mathrm{C}$ for $1 \mathrm{~h}$, where four steps can be distinguished in the heating run. The plateau at temperatures between 700 and $880{ }^{\circ} \mathrm{C}$ is most probably due to the recrystallization. At the same temperatures where the anomaly in the permittivity is observed $\left(400-600{ }^{\circ} \mathrm{C}\right.$ ), a slight change in the slope of the dc conductivity curves can be observed (Figs. 14 and 15). In the ceramic hot pressed at $1050{ }^{\circ} \mathrm{C}$ for $1 \mathrm{~h}$, there are differences in conductivity between the two cuts, being higher for 


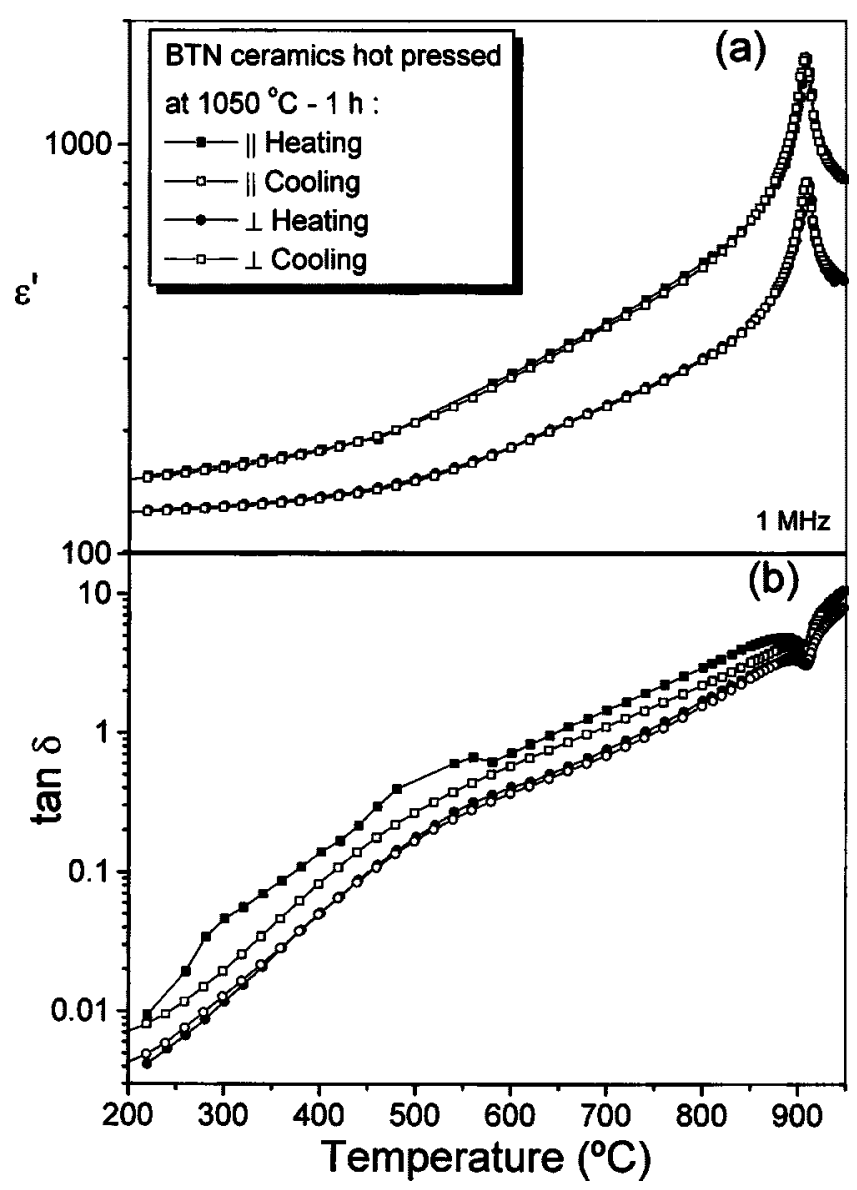

FIG. 9. Real part of dielectric permittivity and dielectric loss factor at $1 \mathrm{MHz}$ as a function of temperature for $\mathrm{Bi}_{3} \mathrm{TiNbO}_{9}$ ceramics hot pressed at $1050{ }^{\circ} \mathrm{C}$ for $1 \mathrm{~h}$ (solid symbols: heating; hollow symbols: cooling).

the parallel to the applied pressure sample cut, which is representative of the properties of the $a-b$ plane of the layer perovskite.

From the Arrhenius plots, the activation energies of each step of the slope on the heating run were calculated, when it was possible, from the expression,

$$
\sigma_{\mathrm{dc}}=\sigma_{0} \exp \left[-\frac{E_{a}}{k T}\right] .
$$

The results are shown in Table I. The highest $E_{a}$ values correspond to the high-temperature range $\left(>700{ }^{\circ} \mathrm{C}\right.$, approximately, HHT in Table I). They vary between 0.65 and $1.06 \mathrm{eV}$, for the ceramic hot pressed at $1050{ }^{\circ} \mathrm{C}$ for $1 \mathrm{~h}$ (parallel to the applied pressure sample cut) and for the ceramic sintered at $1050{ }^{\circ} \mathrm{C}$ for $1 \mathrm{~h}$. The lowest values correspond to the ceramics hot pressed at $700{ }^{\circ} \mathrm{C}$ for $1 \mathrm{~h}\left(E_{a}=0.44 \mathrm{eV}\right)$ and $900{ }^{\circ} \mathrm{C}$ for $1 \mathrm{~h}\left(E_{a}=0.58 \mathrm{eV}\right)$.

The lowest $E_{a}$ values correspond to the low-temperature range $\left(<270{ }^{\circ} \mathrm{C}\right.$, approximately, LT in Table I). No huge differences can be observed among the ceramics. All of them present values of $E_{a}$ of $\sim 0.2 \mathrm{eV}$. It is similar to the one of the flat of the ceramic hot pressed at $700{ }^{\circ} \mathrm{C}$ for $1 \mathrm{~h}$.

The intermediate step $\left(\sim 270-700{ }^{\circ} \mathrm{C}\right.$, HT in Table I) presents values of $E_{a} \sim 0.5 \mathrm{eV}$, except for the ceramic sintered at $1050^{\circ} \mathrm{C}$ for $2 \mathrm{~h}\left(E_{a}=0.65 \mathrm{eV}\right)$ and for the ceramic

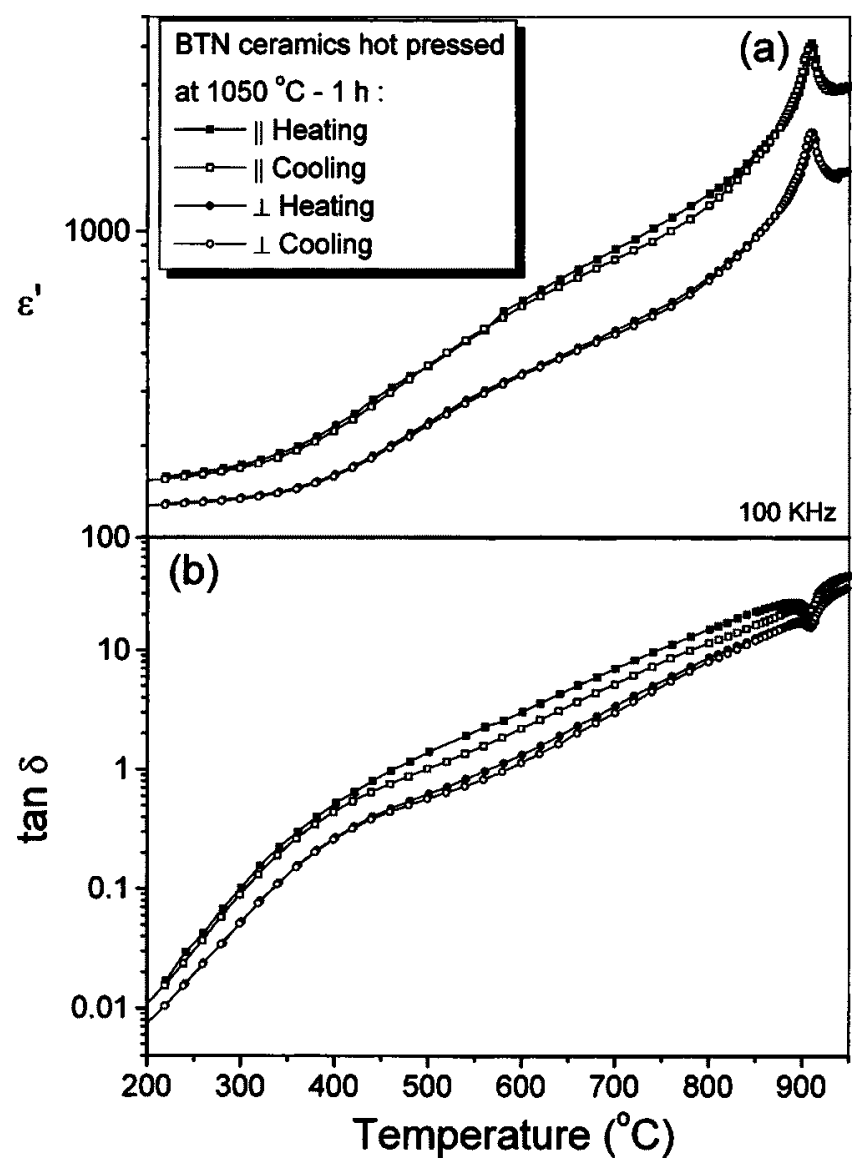

FIG. 10. Real part of dielectric permittivity and dielectric loss factor at $100 \mathrm{KHz}$ as a function of temperature for $\mathrm{Bi}_{3} \mathrm{TiNbO}_{9}$ ceramics hot pressed at $1050{ }^{\circ} \mathrm{C}$ for $1 \mathrm{~h}$ (solid symbols: heating; hollow symbols: cooling).

hot pressed at $1050{ }^{\circ} \mathrm{C}$ for $1 \mathrm{~h}$ (parallel to the applied pressure sample cut), which is slightly lower $\left(E_{a}=0.44 \mathrm{eV}\right)$.

\section{DISCUSSION}

The porosity of the ceramics influences their dielectric properties. Among the sintered ceramics, the one with higher porosity ${ }^{4}\left(1000{ }^{\circ} \mathrm{C}\right.$ for $\left.1 \mathrm{~h}\right)$ has the lower permittivity at low temperatures $\left(\varepsilon^{\prime}=88\right.$ at $\left.300{ }^{\circ} \mathrm{C}\right)$ (Figs. 1-3). The ceramic sintered at $1100{ }^{\circ} \mathrm{C}$ for $2 \mathrm{~h}$ has also a low permittivity $\left(\varepsilon^{\prime}\right.$ $=113$ at $300{ }^{\circ} \mathrm{C}$ ). This latter ceramic presents a bimodal grain area distribution. ${ }^{4}$ As a consequence of an abnormal grain growth, two types of grains with a large difference in grain size can be observed. The regions with larger grains have a higher intergranular porosity that reduces the interconnectivity of the grains and diminishes the permittivity. The inversion of the tendency that results in higher values of permittivity close to the ferroparaelectric phase transition of the ceramic sintered at $1000{ }^{\circ} \mathrm{C}$ for $1 \mathrm{~h}$ is related with its higher conductivity. It has been observed ${ }^{7}$ that a metastable fluorite-type structure appears before it is transformed to an Aurivillius-type structure. In the ceramic sintered at $1000{ }^{\circ} \mathrm{C}$ for $1 \mathrm{~h}$, there can still be small amounts of fluorite phase, which has higher conductivity. ${ }^{24}$

The broadening in the transition of this ceramic is a phenomenon also observed in hot-pressed ceramics, where the porosity has not influence (Figs. 6-8). It indicates that the 


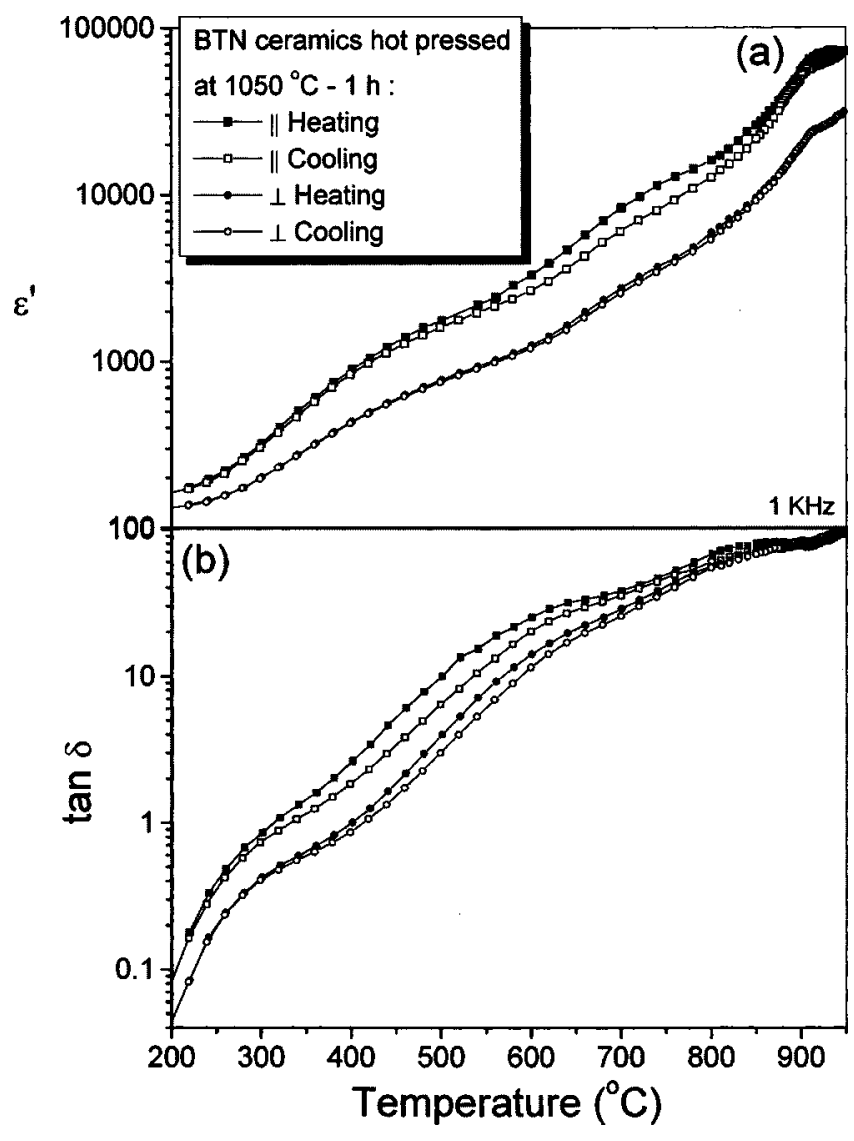

FIG. 11. Real part of dielectric permittivity and dielectric loss factor at $1 \mathrm{KHz}$ as a function of temperature for $\mathrm{Bi}_{3} \mathrm{TiNbO}_{9}$ ceramics hot pressed at $1050{ }^{\circ} \mathrm{C}$ for $1 \mathrm{~h}$ (solid symbols: heating; hollow symbols: cooling).

broadening is related to the grain size. A diffuse phase transition is produced due to an inhomogeneous tension distribution originated by a reduced grain area. ${ }^{25}$ It varies slightly the temperature of the maximum of permittivity from one grain to another. The observed anomaly at the transition would be the convolution of the different transition anomalies.

The slight displacement of the maximum of permittivity to lower temperatures during the cooling run has been observed in the system $\left(\mathrm{SrBi}_{2} \mathrm{Nb}_{2} \mathrm{O}_{9}\right)_{1-x}\left(\mathrm{Bi}_{3} \mathrm{TiNbO}_{9}\right)_{x}$ with $x$ $=0.25,0.50$, and 0.75 . $^{26}$ It is attributed to the defect points that accumulate at the domain walls and create an internal bias field. When domains disappear in the paraelectric phase, a thermal diffusion of the defects occurs, and thus, the disappearance of the internal field when cooling to the ferroelectric phase, since these defects take days to return to their primitive positions. $^{27}$

Hot-pressed ceramics of BTN obtained from mechanically activated precursors have lower porosity ( $\sim 0.5 \%$ of theoretical in all cases) than the sintered ones $(25 \%-8 \%){ }^{8}$ This high densification produces the observed increase of permittivity, if Figs. 1-3 (sintered ceramics) and 6-8 (hot-pressed ceramics) are compared. The influence of the grain area and aspect ratio on the dielectric properties can be observed if isotropic ceramics hot pressed at 700, 900, and $1000{ }^{\circ} \mathrm{C}$ (Figs. 6-8) are compared during the heating run measurements, because porosity is similar and its effect can be neglected. The permittivity diminishes as the hot-
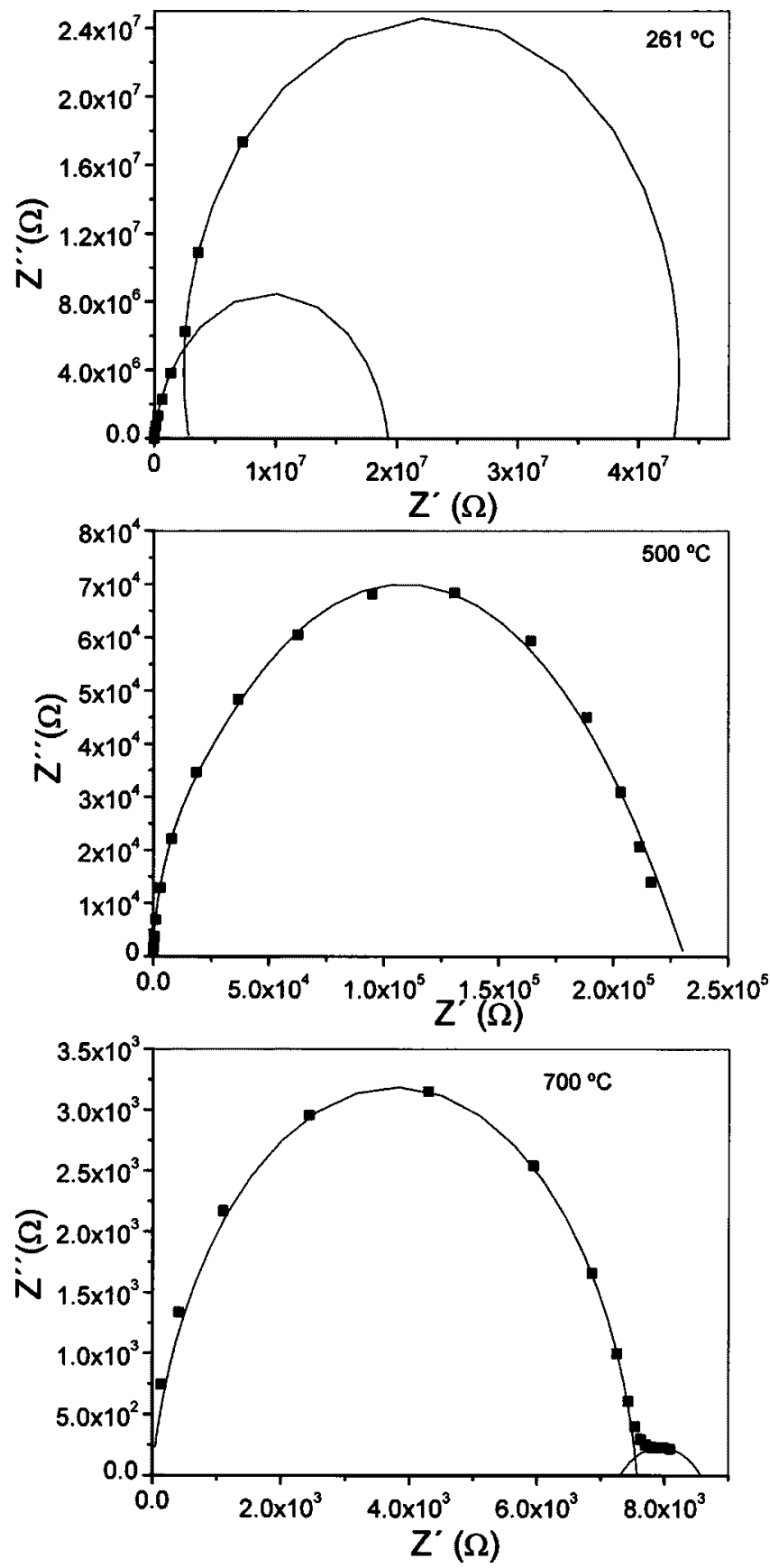

FIG. 12. Complex impedance arcs at 261,500 , and $700{ }^{\circ} \mathrm{C}$ of $\mathrm{Bi}_{3} \mathrm{TiNbO}_{9}$ ceramics sintered at $1100{ }^{\circ} \mathrm{C}$ for $2 \mathrm{~h}$.

pressing temperature increases. The values of $\varepsilon^{\prime}$ at $240{ }^{\circ} \mathrm{C}$ are 250, 201, and 134 for the ceramics hot pressed at 700, 900 , and $1000{ }^{\circ} \mathrm{C}$, respectively. This result can be explained taking into account that when the hot-pressing temperature increases the grain area and the aspect ratio also increase. ${ }^{8}$ As it was previously reported, the maximum length of the grains varies from the $0.2 \mu \mathrm{m}$ and equiaxial ${ }^{9}$ grains (aspect ratio $\sim 1$ ), for ceramics hot pressed at $700{ }^{\circ} \mathrm{C}$ for $1 \mathrm{~h}$, to $1.7 \mu \mathrm{m}$ (aspect ratio $\sim 2.0$ ) for ceramics hot pressed at $1000{ }^{\circ} \mathrm{C}$ for $1 \mathrm{~h}^{8}{ }^{8}$ The reduction of the permittivity and the dielectric losses at the temperature of the maximum as frequency increases seems to be due to mobile charges related with defects (oxygen vacancies mainly) ${ }^{28}$ that also influences the conductivity. As it will be analyzed in the following, the 

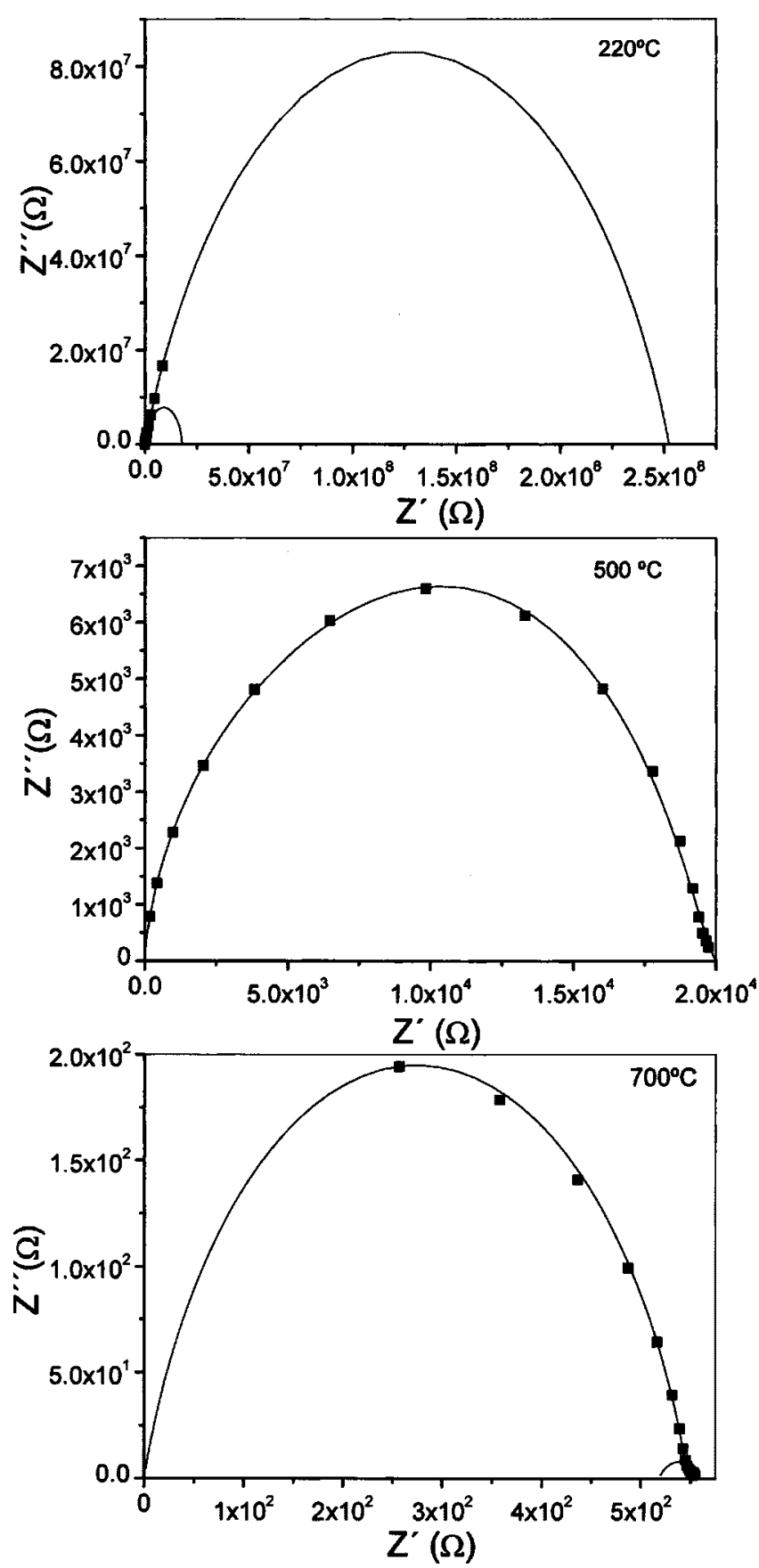

FIG. 13. Complex impedance arcs at 220,500 , and $700{ }^{\circ} \mathrm{C}$ of $\mathrm{Bi}_{3} \mathrm{TiNbO}_{9}$ ceramics hot pressed at $700{ }^{\circ} \mathrm{C}$ for $1 \mathrm{~h}$.

reduction in the aspect ratio increases the conductivity of the materials, which influences the dielectric permittivity. Thus, the increase in $\varepsilon^{\prime}$ in fine-grained hot-pressed BLSF ceramics is related with the anisotropic growth habit of these structures, which hot pressing inhibits.

The percolation effective-medium theory model developed by Pecharromán and Iglesias, ${ }^{29}$ and applied by Jiméne $\mathrm{z}^{30}$ has been used to study the grain shape effect in the conductivity of the ceramics. In the model, a random distribution of spheroid particles with different conductivities in the $c$ axis and the $a-b$ plane perpendicular to it (assuming a ratio $\sigma_{c} / \sigma_{a-b}=1 / 10$, in reasonable agreement with the experimental data for BTN, Fig. 15) is considered. Neither the

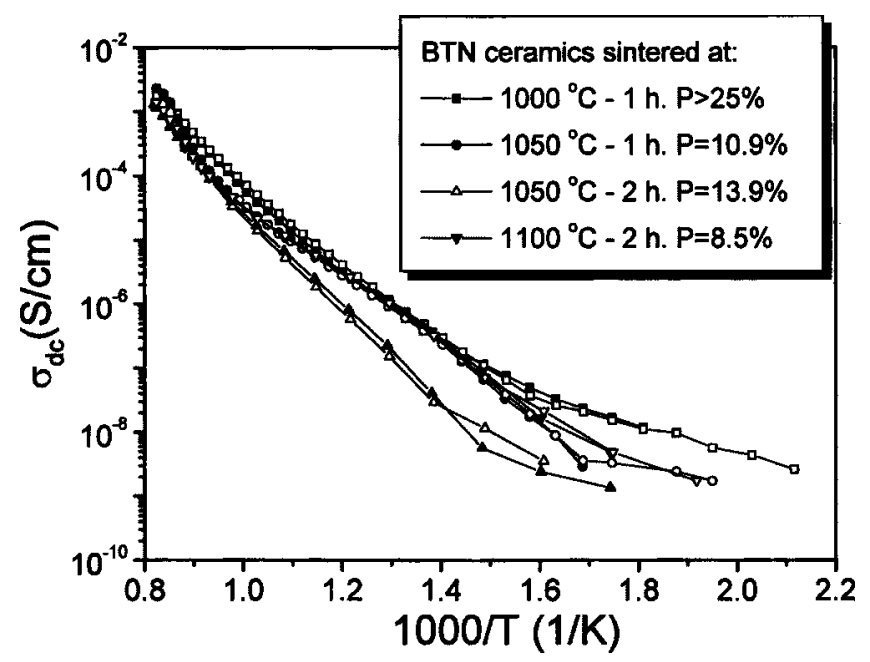

FIG. 14. Arrenhius plot of the dc conductivity for $\mathrm{Bi}_{3} \mathrm{TiNbO}_{9}$ sintered ceramics (solid symbols: heating; hollow symbols: cooling).

influence of the grain boundary nor the one of the domain walls has been considered for these calculations. Increasing the filling factor of the samples (that is, decreasing the porosity), conductivity increases, as it is observed in the ceram-
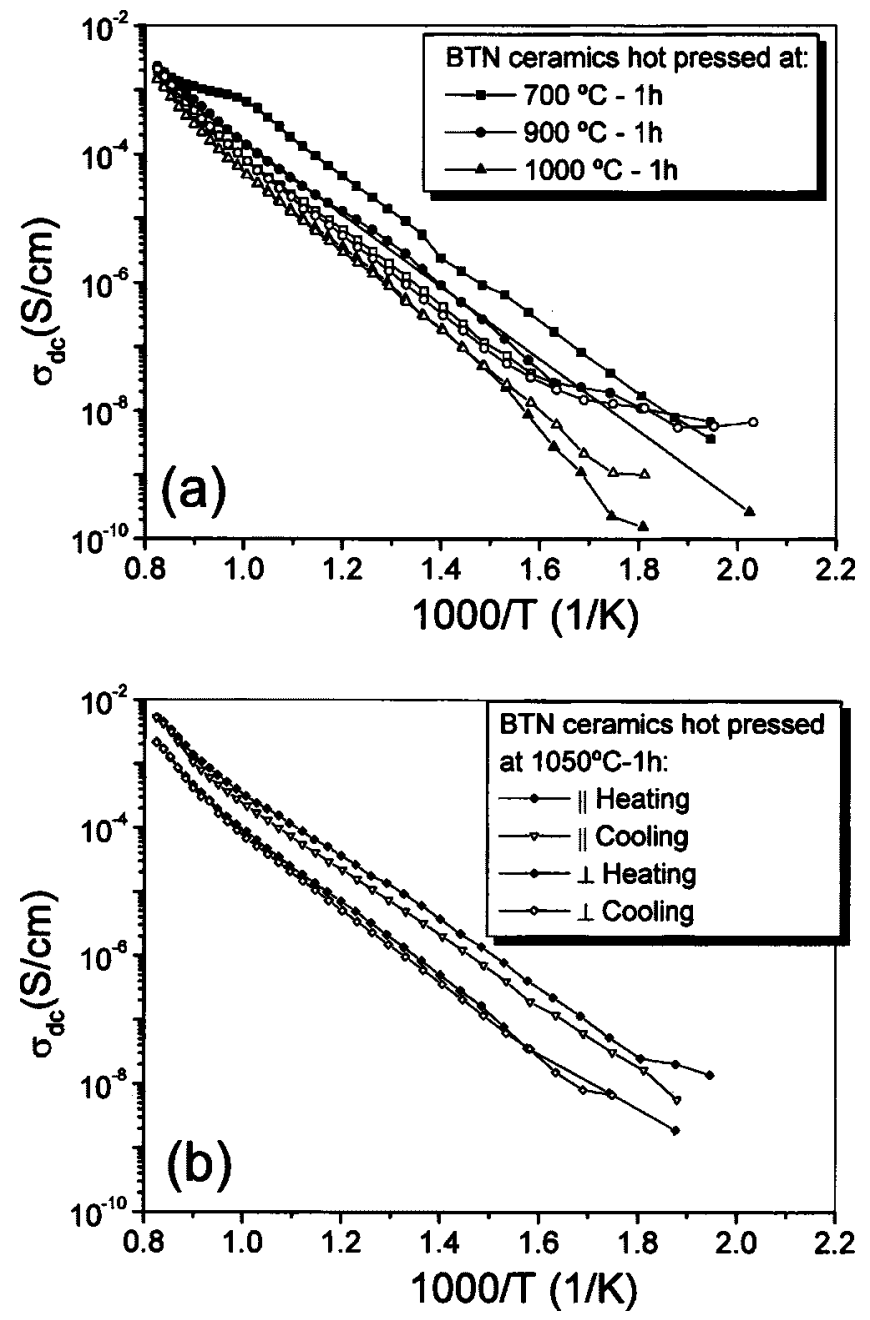

FIG. 15. Arrherius plot of the dc conductivity for $\mathrm{Bi}_{3} \mathrm{TiNbO}_{9}$ hot-pressed ceramics: (a) $700-1000{ }^{\circ} \mathrm{C}-1 \mathrm{~h}$; (b) $1050{ }^{\circ} \mathrm{C}-1 \mathrm{~h}$ (solid symbols: heating; hollow symbols: cooling). 
TABLE I. Activation energy obtained from the Arrhenius plot of sintered and hot-pressed $\mathrm{Bi}_{3} \mathrm{TiNbO}_{9}$ ceramics.

\begin{tabular}{|c|c|c|c|c|c|}
\hline \multicolumn{6}{|c|}{ Sintered ceramics } \\
\hline Sample & $1000^{\circ} \mathrm{C}-1 \mathrm{~h}$ & $1050^{\circ} \mathrm{C}-1 \mathrm{~h}$ & $1050^{\circ} \mathrm{C}-2 \mathrm{~h}$ & $1100^{\circ} \mathrm{C}-2 \mathrm{~h}$ & \\
\hline$E_{a}(\mathrm{eV})(\mathrm{HHT})$ & 0.76 & 1.06 & 0.87 & 1.01 & \\
\hline$E_{a}(\mathrm{eV})(\mathrm{HT})$ & 0.50 & 0.49 & 0.65 & 0.47 & \\
\hline$E_{a}(\mathrm{eV})(\mathrm{LT})$ & 0.24 & $\cdots$ & 0.20 & $\cdots$ & \\
\hline \multicolumn{6}{|c|}{ Hot-pressed ceramics } \\
\hline Sample & $700{ }^{\circ} \mathrm{C}-1 \mathrm{~h}$ & $900{ }^{\circ} \mathrm{C}-1 \mathrm{~h}$ & $1000^{\circ} \mathrm{C}-1 \mathrm{~h}$ & $1050^{\circ} \mathrm{C}-1 \mathrm{~h}(\|)$ & $1050^{\circ} \mathrm{C}-1 \mathrm{~h}(\perp)$ \\
\hline$E_{a}(\mathrm{eV})(\mathrm{HHT})$ & 0.44 & 0.58 & 0.75 & 0.65 & 0.77 \\
\hline & Flat: 0.17 & & & & \\
\hline$E_{a}(\mathrm{eV})(\mathrm{HT})$ & 0.49 & 0.50 & 0.57 & 0.44 & 0.48 \\
\hline$E_{a}(\mathrm{eV})(\mathrm{LT})$ & $\cdots$ & 0.17 & $\cdots$ & 0.16 & $\cdots$ \\
\hline
\end{tabular}

ics of this work if sintered and hot-pressed ones [Figs. 14 and 15(a)] are compared. Regardless of the filling factor, bulk conductivity decreases as the ratio $c / a$ (with $a=b$ ) has lower values, as Fig. 16 shows. This axial relation is developed as the treatment temperature increases, ${ }^{8}$ so conductivity should decrease as it happens in our case with the hotpressed ceramics, in which the negligible porosity achieved allows a comparison of different grain sizes and shapes [Fig. 15(a)]. The model predicts the structural (crystallographic) factors contribution to the conductivity. To fully explain the dc conductivity trends experimentally observed here, contributions of grain boundaries and domain walls must be taken into account.

The dc conductivity of Figs. 14 and 15 has been obtained from the complex impedance arcs. Depending on the temperature of the measurement, 1 or 2 different semicircles can be adjusted from the experimental data (Figs. 12 and 13). In previous works, these subcircuits have been usually identified as corresponding to the grain (bulk), grain boundary, or electrode/ceramic interface conduction, depending on the frequency interval where they appear. ${ }^{31}$ The total conductivity of the material is taken as the sum in series of each component. Total impedance is dominated by the component with the highest $R$. However, similar appearance of arcs as temperature increases has been reported in BLSF single crystals ${ }^{32}$ where there are not grain boundaries.

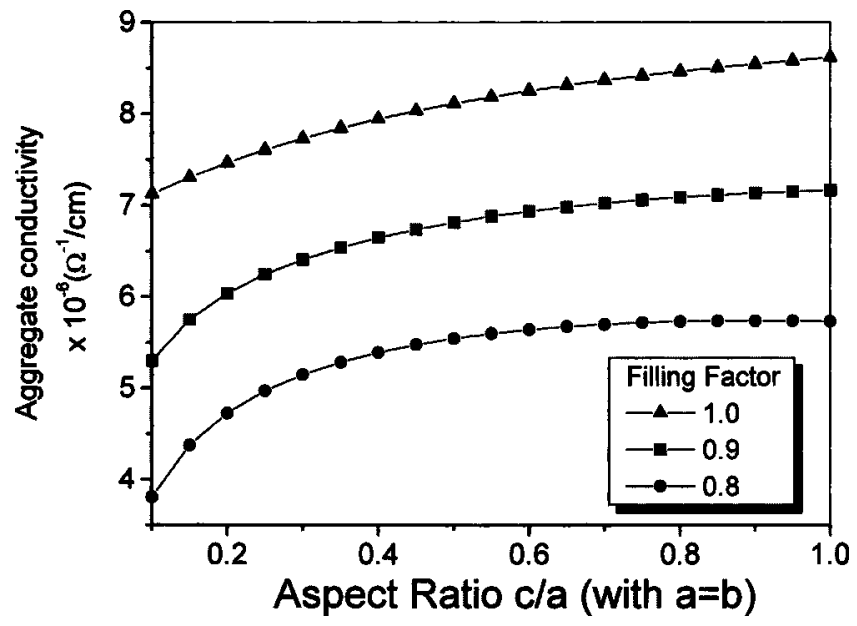

FIG. 16. Conductivity calculated as a function of the aspect ratio for a random spheroid distribution with a ratio $\sigma_{c} / \sigma_{a-b}=1 / 10$.
At the low-temperature step $\left(<270{ }^{\circ} \mathrm{C}\right)$ in the slope of the Arrhenius plot, two semicircles are distinguished (Figs. 12 and 13). In a previous study, ${ }^{32}$ the higher-frequency arc was attributed to the impedance of the $\left(\mathrm{Bi}_{2} \mathrm{O}_{2}\right)^{2+}$ layer, with higher resistivity than the pseudoperovskite block. This can be supported by the fact that the conductivity has the same behavior (low and almost constant) at low temperatures in all BLSF materials. The common element to all of them is the $\left(\mathrm{Bi}_{2} \mathrm{O}_{2}\right)^{2+}$ layer, which determines the conductivity in the low-temperature range. It is observed in Figs. 12 and 13 that, as temperature increases, only one semicircle appears. It corresponds to the intermediate temperature $\left(\sim 270-700{ }^{\circ} \mathrm{C}\right)$ step of the Arrhenius plot (Figs. 14 and 15). The activation energy calculated in that range is $\sim 0.5 \mathrm{eV}$. This value is close to the one found in other BLSF ceramics with $n=2,{ }^{33}$ and corresponds to thermally activated oxygen vacancies diffusion. The conduction by oxygen vacancies is known to be produced through the perovskite layers in BLSF materials. ${ }^{34}$ The change in conductivity at certain temperature is due to the change of conduction from $\left(\mathrm{Bi}_{2} \mathrm{O}_{2}\right)^{2+}$ to perovskite layers.

A further increase of the temperature measurement produces the appearance of a second impedance arc (Figs. 12 and 13). The activation energy calculated in this step varies from 0.65 to $1.06 \mathrm{eV}$, which are far from the values of $\sim 1.5 \mathrm{eV}$ resulting from an electron-transfer reaction at the electrode-ferroelectric interface. ${ }^{31}$ Thus, it must be concluded that the high-temperature impedance arc does not correspond to the ceramic-electrode interface but to the grain boundaries. It becomes more important as temperature increases. This would explain that the fine-grained ceramics ${ }^{9}$ $(<1 \mu \mathrm{m})$ hot pressed at moderate temperatures $\left(700 / 900{ }^{\circ} \mathrm{C}\right.$ for $1 \mathrm{~h}$ ), with higher grain-boundary density, have the highest conductivity, as shown in Fig. 15.

The influence of domain walls can be studied in the highest-temperature range $\left(>900{ }^{\circ} \mathrm{C}\right)$. The fact that Arrhenius plots converge above the transition temperature to the paraelectric phase (Figs. 14 and 15), where there are no ferroelectric domains, seems to show that these have some influence in dc conductivity, although they have not been taken into account in the model. It has been suggested ${ }^{26}$ that there is a pinning charge in the non- $180^{\circ}$ domain walls. Finegrained ceramics do not favor the domain creation. In this case, the charge is not pinned but free, and conductivity in- 
creases. In the paraelectric phase, domains disappear in all cases, and conductivity approaches to that predicted by the model, where the influence of grain boundaries or domains is not taken into account. On cooling, the charge pins again at the domain walls but in a much lesser extend. ${ }^{27}$ This produces the slight thermal hysteresis, and the conductivity measured on the cooling run becomes lower. Cooling run should not be compared in ceramics hot pressed at $700{ }^{\circ} \mathrm{C}$ for $1 \mathrm{~h}$ and $900{ }^{\circ} \mathrm{C}$ for $1 \mathrm{~h}$ due to the change in the microstructure that takes place in these ceramics during the measurements.

As it has been said, the conductivity has a great effect in the permittivity of the ceramics. The curves of $\varepsilon^{\prime}$ (Figs. 6-11) and the Arrhenius plot (Figs. 14 and 15) have anomalies in the same ranges of temperature, which is something common in ceramics with an Aurivillius-type structure. ${ }^{35,36}$ In other compositions, as in $\mathrm{Bi}_{4} \mathrm{Ti}_{3} \mathrm{O}_{12}$, it is accepted that anomalies are produced by an ion-jump thermally activated mechanism that produces a dipole relaxation. ${ }^{35}$ It occurs in the $a-b$ plane and should not affect the conductivity. In our case, the anomalies in $\varepsilon^{\prime}$ also appear in the perpendicular cut (representative of the properties of the $c$ axis) of the ceramic hot pressed at $1050{ }^{\circ} \mathrm{C}$ for $1 \mathrm{~h}$ (Fig. 11). The conductivity also presents anomalies in the heating and in the cooling runs in all cases (Figs. 14 and 15). In similar composition the ion-jump mechanism contribution explains the irreversible anomalies found in the heating run for $\varepsilon^{\prime} .{ }^{36}$ The anomaly observed here may have another origin. A ferro-ferroelectric phase transition, reported by other authors ${ }^{37,38}$ in the same range of temperature for this composition, determines most probably the appearance of the reversible anomalies (in the range of $400-600{ }^{\circ} \mathrm{C}$ ) in the dielectric properties of BTN ceramics.

The anisotropy in $1050{ }^{\circ} \mathrm{C}$ for $1 \mathrm{~h}$ hot-pressed ceramic is a well-known phenomenon ${ }^{18}$ in the Aurivillius-type ceramics and it is a texture consequence. It has been observed in single crystals that permittivity is higher in the plane perpendicular to the $c$ axis than along this. ${ }^{39-41}$ At $1050{ }^{\circ} \mathrm{C}$ for $1 \mathrm{~h}$, the grains arrange with the $c$ axis parallel to the applied pressure. In the so-called parallel cut the $a-b$ plane contribution to $\varepsilon^{\prime}$, which contains the ferroelectric axis, is measured. Thus, the sample in this direction has a higher $\varepsilon^{\prime}$ value (Figs. 9-11), and the perpendicular direction has the lowest value of all the measured ceramics. In general, the values of permittivity lie between the values of the parallel and perpendicular to the $c$-axis cuts. Close to room temperature $\left(240{ }^{\circ} \mathrm{C}\right), \varepsilon^{\prime}=155$ at $1 \mathrm{MHz}$ for the parallel cut of the ceramic hot pressed at $1050{ }^{\circ} \mathrm{C}$ for $1 \mathrm{~h}$ (Fig. 9). It is lower than the values for the ceramics hot pressed at $700\left(\varepsilon^{\prime}=250\right)$ and $900{ }^{\circ} \mathrm{C}$ for $1 \mathrm{~h}$ $\left(\varepsilon^{\prime}=201\right.$, Fig. 6). In this case the influence of a lower grain size in the permittivity of an isotropic ceramic is even more important than the influence of the texture. It proves that the control of microstructure, by the use of moderate hotpressing temperatures in mechanically activated precursors, allows the processing of ceramics with very high values of $\varepsilon^{\prime}$.

The difference in the conductivity between both sample cuts of the ceramics hot pressed at $1050{ }^{\circ} \mathrm{C}$ for $1 \mathrm{~h}$ (Fig. 13) is also a consequence of the texture. ${ }^{18}$ In the parallel cut, the conductivity is measured in the $a-b$ plane, which in Aurivillius-type structure ceramics is higher than along the $c$ axis. The $\left[\mathrm{Bi}_{2} \mathrm{O}_{2}\right]^{2+}$ layers act as barriers to the charge transports. ${ }^{32,39,41}$ Thus, the conduction is mainly produced in the perovskite planes and conductivity increases.

\section{CONCLUSIONS}

Ceramics with controlled texture and microstructure and $\mathrm{Bi}_{3} \mathrm{TiNbO}_{9}$ (BTN) nominal composition, processed by sintering and hot pressing of mechanically activated precursors, have been studied. Since the use of such ceramic precursors allows the control of texture and microstructure, it is possible to tailor the ceramic properties accordingly, since:

Sintered isotropic ceramics have a lower dielectric permittivity than the hot-pressed ceramics, due to their higher porosity. Dielectric loss factor is also higher in hot-pressed ceramics, mainly due to the increase in dc conductivity.

In hot pressed isotropic ceramics at 700, 900, and $1000{ }^{\circ} \mathrm{C}$, with similar and negligible porosity but different grain sizes, the permittivity increases as the area and the aspect ratio of the grains are reduced, due to the anisotropy of the dielectric properties of the grains related with the crystalline structure.

The dc conductivity of the isotropic ceramics becomes larger when porosity is reduced, and decreases as permittivity when the grain size grows and the $c / a$ (with $a=b$ ) relation decreases. The effect of charged defects, that are not pinned in the non- $180^{\circ}$ domain walls of fine-grained ceramics, and the contributions of grain boundaries mainly at high temperatures, also contribute to increase their conductivity.

As it is well known in BLSF ceramics, the developed texture in ceramics hot pressed at $1050{ }^{\circ} \mathrm{C}$ produces differences in permittivity and conductivity when measured in perpendicular and parallel to applied pressure cuts. The latter have higher values in both cases.

\section{ACKNOWLEDGMENTS}

The authors thank the research projects 07N/0076/2002 of Spanish CAM and MAT2001-0561 of Spanish MCyT for the financial support of this work. Collaboration of Dr. A. Castro in the processing of high-quality and well characterized mechanically activated precursors and of Dr. R. Jiménez on the conductivity calculations are acknowledged.

${ }^{1}$ B. Aurivillius, Ark. Kemi 1, 463 (1949).

${ }^{2}$ T. R. Shrout, R. Eitel, and C. Randall, Piezoelectric Materials in Devices (N. Setter, Lausanne, 2002), Chap. 19

${ }^{3}$ C. A. Paz de Araujo, J. D. Cuchiaro, L. D. McMillan, M. C. Scott, and J. F. Scott, Nature (London) 374, 627 (1995).

${ }^{4}$ L. Pardo, A. Moure, A. Castro, P. Millán, C. Alemany, and B. Jiménez, Bol. Soc. Esp. Ceram. Vidrio 38, 563 (1999).

${ }^{5}$ H. Igarashi, K. Matsunaga, T. Tianiai, and K. Okazaki, Am. Ceram. Soc. Bull. 57, 815 (1978)

${ }^{6}$ P. Durán-Martin, Doctoral thesis, UAM, 1997.

${ }^{7}$ A. Castro, P. Millán, L. Pardo, and B. Jiménez, J. Mater. Chem. 9, 1313 (1999).

${ }^{8}$ A. Moure, L. Pardo, C. Alemany, P. Millán, and A. Castro, J. Eur. Ceram. Soc. 21, 1399 (2001).

${ }^{9}$ J. Ricote, L. Pardo, A. Moure, A. Castro, P. Millán, and D. Chateigner, J. Eur. Ceram. Soc. 21, 1403 (2001).

${ }^{10}$ G. Arlt, D. Hennings, and G. de With, J. Appl. Phys. 58, 1619 (1985).

${ }^{11}$ C. A. Randall, N. Kim, J. P. Kucera, W. Cao, and T. R. Shrout, J. Am. 
Ceram. Soc. 81, 677 (1998)

${ }^{12}$ J. Ricote, C. Alemany, L. Pardo, and C. E. Millar, Acta Mater. 44, 1169 (1996).

${ }^{13}$ H. S. Shulman, M. Testorf, D. Damjanovic, and N. Setter, J. Am. Ceram. Soc. 79, 3124 (1996).

${ }^{14}$ M. Villegas, A. C. Caballero, C. Moure, P. Durán, and J. F. Fernández, J. Am. Ceram. Soc. 82, 2411 (1999).

${ }^{15}$ S. H. Hong, J. A. Horn, S. Troiler-McKinstry, and G. L. Messing, J. Mater. Sci. Lett. 19, 1661 (2000)

${ }^{16}$ Z. Z. Huang, H. L. W. Chan, K. W. Kwok, and C. L. Choy, J. Mater. Sci. 38, 1793 (2000)

${ }^{17}$ Z. Zhang, H. Yan, X. Dong, and Y. Wang, Mater. Res. Bull. 38, 241 (2003).

${ }^{18}$ Z. Zhang, H. Yan, P. Xiang, X. Dong, and Y. Wang, J. Am. Ceram. Soc. 87, 602 (2004).

${ }^{19}$ J. Ricote and L. Pardo, Acta Mater. 44, 1155 (1996).

${ }^{20}$ T. Allen, Particle Size Measurements (Chapman and Hall, London, 1981), Chap. 4.

${ }^{21}$ S. K. Kurtz and F. M. A. Carpay, J. Appl. Phys. 51, 5745 (1980).

${ }^{22}$ B. A. Boukamp, Solid State Ionics 20, 31 (1986).

${ }^{23}$ A. Moure, A. Castro, and L. Pardo, Acta Mater. 52, 945 (2004).

${ }^{24}$ P. Begué, P. Millán, and A. Castro, Bol. Soc. Esp. Ceram. Vidrio 38, 558 (1999).

${ }^{25}$ H. T. Martinera and J. C. Burfoot, J. Phys. C 7, 3182 (1974).

${ }^{26}$ B. Jiménez, A. Castro, L. Pardo, P. Millán, and R. Jiménez, J. Phys. Chem.
Solids 62, 951 (2001).

${ }^{27}$ B. Jiménez, R. Jiménez, A. Castro, P. Millán, and L. Pardo, J. Phys.: Condens. Matter 13, 7315 (2001).

${ }^{28}$ S. Ezhilvalavan, J. M. Xue, and J. Wang, Mater. Chem. Phys. 75, 50 (2002).

${ }^{29}$ C. Pecharromán and J. E. Iglesias, Phys. Rev. B 49, 7137 (1994).

${ }^{30}$ R. Jiménez, Solid State Ionics 92, 225 (1996).

${ }^{31}$ T. C. Chen, C. L. Thio, and S. B. Desu, J. Mater. Res. 12, 2628 (1997).

${ }^{32}$ S. K. Kim, M. Miyayama, and H. Yanagida, Mater. Res. Bull. 31, 121 (1996).

${ }^{33}$ P. Durán-Martín, A. Castro, P. Millán, and B. Jiménez, J. Mater. Res. 13, 2565 (1998).

${ }^{34}$ M. Takahashi, Y. Noguchi, and M. Miyayama, Jpn. J. Appl. Phys., Part 1 41, 7053 (2002).

${ }^{35}$ H. S. Shulman, D. Damjanovic, and N. Setter, J. Am. Ceram. Soc. 83, 528 (2000).

${ }^{36}$ B. Jiménez, A. Castro, L. Pardo, P. Millán, and R. Jiménez, J. Phys. Chem. Solids 62, 951 (2001).

${ }^{37}$ E. C. Subbarao, Phys. Chem. Solids 23, 665 (1962).

${ }^{38}$ R. L. Withers, R. W. Wolfe, and J. F. Dorrian, Mater. Res. Bull. 6, 1029 (1971).

${ }^{39}$ L. Fouskova and L. E. Cross, J. Appl. Phys. 41, 2834 (1970).

${ }^{40}$ R. Maalal, R. Von der Mühll, G. Trolliard, and J. P. Mercurio, J. Phys. Chem. Solids 52, 1957 (1996).

${ }^{41}$ I. S. Yi and M. Miyayama, Mater. Res. Bull. 32, 1349 (1997). 